Note

\section{Properties of Xylanase of Malbranchea pulchella var. sulfurea No. 48}

\author{
Masaru Matsuo and Tsuneo Yasui \\ Institute of Applied Biochemistry, \\ The University of Tsukuba, \\ Ibaraki 305, Japan
}

Received March 27, 1984

Except for the recent papers by Hayashida et al.$^{1,2)}$ on Xylanase from Talaromyces byssochlamydoides, there has been no report on xylanases from thermophilic fungi with respect to their enzymic properties in the pure state. In our previous papers, ${ }^{3 \sim 6)}$ we reported that a $\beta$-xylosidase [EC 3.2.1.37 exo-1,4- $\beta$-D-xylosidase] was purified from a culture filtrate of Malbranchea pulchella var. sulfurea No. 48, and its properties were investigated in detail. The purpose of this work is to purify an endo-type xylanase [EC 3.2.1.8 endo-1,4- $\beta$-D-xylanase] from a culture filtrate of a Malbranchea strain and to study some properties of the purified enzyme. Here the expression xylanase refers to the endo-type xylanase where not otherwise specified.

The xylanase from $M$. pulchella var. sulfurea No. 48 was purified 139-fold from a culture filtrate by ammonium sulfate fractionation and column chromatographies on DEAE-cellulose and CM-Sephadex (Table I). The yield of purified enzyme activity from a culture filtrate was $42.8 \%$. The homogeneity of the purified enzyme was examined by polyacrylamide gel disc electrophoresis ${ }^{7}$ and a single protein band was obtained. The purified xylanase had an isoelectric point at $\mathrm{pH} 8.6$, the optimum $\mathrm{pH}$ in the range between 6.0 and 6.5 , and the optimum temperature at $70^{\circ} \mathrm{C}$.

Xylanase activity was estimated by measuring the viscosity reduction of the substrate solution using soluble xylan (hard wood) ${ }^{4)}$ The reaction mixture consisted of $5 \mathrm{ml}$ of $2 \%$ soluble xylan solution, $4 \mathrm{ml}$ of $0.01 \mathrm{M}$ phosphate buffer solution (pH 6.5), and $1 \mathrm{ml}$ of enzyme solution. After $5 \mathrm{~min}$ of incubation at $45^{\circ} \mathrm{C}$ in an Ostwald-type

Table I. Sum of the Purification of Malbranchea Xylanase

\begin{tabular}{lccccc}
\hline \multicolumn{1}{c}{ Purification step } & $\begin{array}{c}\text { Volume } \\
(\mathrm{ml})\end{array}$ & $\begin{array}{c}\text { Total protein } \\
(\mathrm{mg})\end{array}$ & $\begin{array}{c}\text { Total activity } \\
(\mathrm{U})\end{array}$ & $\begin{array}{c}\text { Specific activity } \\
(\mathrm{U} / \mathrm{mg} \cdot \text { protein })\end{array}$ & $\begin{array}{c}\text { Yield } \\
(\%)\end{array}$ \\
\hline Culture filtrate & 6,700 & 38,760 & 45,220 & 1.16 & 100 \\
$80 \%$-satd. $\left(\mathrm{NH}_{4}\right)_{2} \mathrm{SO}_{4}$ ppt. & 208 & 4,320 & 30,932 & 7.16 & 68.4 \\
DEAE-cellulose & 660 & 552 & 22,204 & 40.2 & 49.1 \\
CM-Sephadex & 30 & 120 & 19,355 & 161 & 42.8 \\
\hline
\end{tabular}

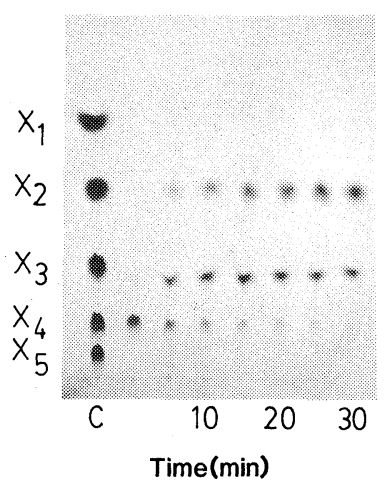

(A)

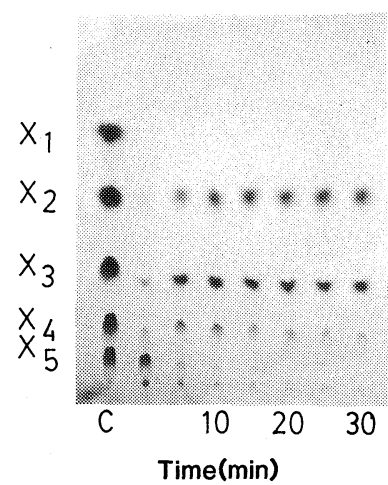

(B)

FIG. 1. Paper Chromatogram of Xylotetraose and Xylopentaose Hydrolyzates by Malbranchea Xylanase.

The reaction mixture, containing $10 \mathrm{mg}$ of xylotetraose and $18 \mathrm{U}$ of the purified xylanase in $5 \mathrm{ml}$ of $0.01 \mathrm{M}$

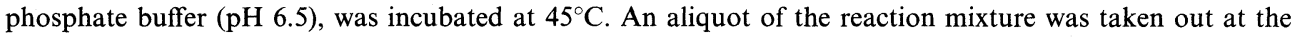
times indicated in the figure and the samples were chromatographed by double ascending development with 1butanol-pyridine-water $(6: 4: 3, \mathrm{v} / \mathrm{v})$ and developed with $p$-anisidine hydrochloride. $\mathrm{C}$, control; $\mathrm{X}_{1}$, $\mathrm{xylose}$; $\mathrm{X}_{2}$, xylobiose; $\mathrm{X}_{3}$, xylotriose; $\mathrm{X}_{4}$, xylotetrose; $\mathrm{X}_{5}$, xylopentaose.

(A), xylotetraose; (B), xylopentaose. 


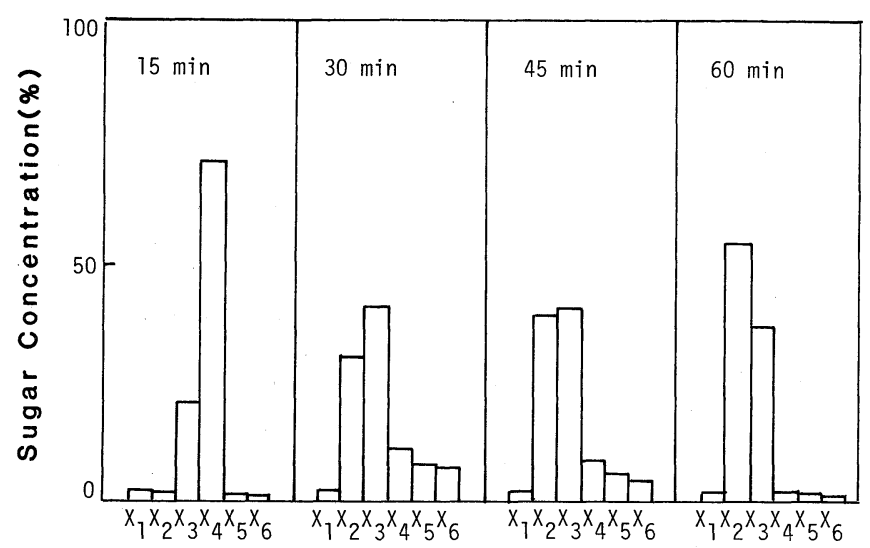

FIG. 2. Diagrams of Xylotetraose Hydrolyzates by Malbranchea Xylanase.

The reaction mixture, containing $10 \mathrm{mg}$ of xylotetraose and $6 \mathrm{U}$ of the purified xylanase in $5 \mathrm{ml}$ of $0.01 \mathrm{M}$ phosphate buffer ( $\mathrm{pH} 6.5$ ), was incubated at $45^{\circ} \mathrm{C}$. An aliquot of the reaction mixture was taken out at the times indicated in the figure, and boiled to inactivate the enzyme. A sample of hydrolyzate was separated by the ascending development method as described in Fig. 1, and a reference marker strip was used to detect the position of the sugars, which were eluted from the paper and their amounts determined by the Orcinol-ferric method.

$\mathrm{X}_{1}$, xylose; $\mathrm{X}_{2}$, xylobiose; $\mathrm{X}_{3}$, xylotriose; $\mathrm{X}_{4}$, xylotetraose; $\mathrm{X}_{5}$, xylopentaose; $\mathrm{X}_{6}$, oligosaccharides higher than $\mathrm{X}_{6}$.

viscometer, the flow time was measured. The value of viscosity reduction $\alpha_{\text {(obs.) }}$ was expressed as $\alpha_{\text {(obs.) }}=$ $\left(t_{\mathrm{r}}-t_{\mathrm{w}}\right) /\left(t_{\mathrm{o}}-t_{\mathrm{w}}\right)$, where $t_{\mathrm{o}}$ was the flow time of the reaction mixture at zero time, $t_{\mathrm{r}}$ was the flow time of the reaction mixture after $5 \mathrm{~min}$, and $t_{\mathrm{w}}$ was the flow time of water. The activity was determined graphically, by plotting the reciprocal values of the viscosity reduction against the amount of enzyme applied. The resulting slopes of the straight lines provide the values of the activity. A unit of enzyme activity was defined as follows: $1-\alpha_{\text {(obs.) }}$

In the degradation of both xylotetraose ${ }^{8)}$ and xylopentaose $^{8)}$ by Malbranchea xylanase, oligosaccharides that were of greater chain length than the substrate sugar were observed on the paper chromatogram (p.p.c.). As shown with the example of xylotetraose (Fig. 1), the first products to be formed were mainly larger products than the substrate sugar. Then their concentration continuously decreased. Xylobiose and xylotriose were formed after a short lag but not xylose. After prolonged reaction, the substrate sugar and larger products disappeared and xylose was formed. Xylose, xylobiose, and xylotriose were found as end products of xylotetraose degradation. This might indicate that there was transglycosylation in the degradation of both xylotetraose and xylopentaose, as shown in Fig. 1. Further, it seemed reasonable that xylobiose and xylotriose formation was a result of degradation of larger products than the substrate sugar in above cases, but further work is required to clarify this point.

Xylan was hydrolyzed approximately $51 \%$ by the purified enzyme and end products were found to be xylose,

\section{Table II. Hydrolysis of Various Glycosides BY Malbranchea XYLANASE}

The reaction mixture, containing $2 \mathrm{ml}$ of a glycoside solution, $1 \mathrm{ml}$ of $0.02 \mathrm{M}$ phosphate buffer $(\mathrm{pH} 6.5)$ and $1 \mathrm{ml}$ of enzyme solution $(0.67 \mathrm{U} / \mathrm{ml})$, was incubated at the indicated concentration of glycosides at $45^{\circ} \mathrm{C}$. After $30 \mathrm{~min}$, the reducing sugar liberated was measured. The enzyme activity for each glycoside was expressed in terms of its value relative to that xylan.

\begin{tabular}{lcc}
\hline Glycoside & $\begin{array}{c}\text { Substrate } \\
\text { concentration } \\
\left(\times 10^{-12} \mathrm{M}\right)\end{array}$ & $\begin{array}{c}\text { Relative } \\
\text { activity } \\
(\%)\end{array}$ \\
\hline Xylobiose & 1 & $0^{b}$ \\
Phenyl $\beta$-D-xyloside & 1 & $0^{b}$ \\
Xylotriose & 1 & $0.1^{b}$ \\
Xylotetraose & 1 & 4 \\
Xylopentaose & 1 & 51 \\
Xylan & $1^{a}$ & 100 \\
\hline
\end{tabular}

a Concentration $(\%)$.

${ }^{b}$ One $\mathrm{ml}$ of enzyme solution $(6.7 \mathrm{U} / \mathrm{ml})$ was used and the reaction time was $10 \mathrm{hr}$.

Reducing sugar was measured by the SomogyiNelson ${ }^{10)}$ and Somogyi ${ }^{11)}$ methods.

xylobiose, and xylotriose on p.p.c. as above noted in xylotetraose degradation.

In order to estimate the amount of hydrolysis products at various stages, each saccharide was eluted from the 
paper and their amounts were determined by the Orcinolferric method $^{9)}$ (Fig. 2). The substrate specificity of purified xylanase toward various $\beta$-xylosides was tested. As shown in Table II, xylobiose and phenyl $\beta$-D-xyloside ${ }^{3)}$ were not hydrolyzed by Malbranchea xylanase.

In conclusion, we assumed that the findings with the degradation of both xylotetraose and xylopentaose were essentially similar to the other cases reporting the degradation of both maltotetraose and maltopentaose with $\alpha$-amylase. ${ }^{12)}$ Moreover, it was clear that xylotetraose and higher oligosaccharides were readily hydrolyzed by Malbranchea xylanase, xylotriose was very resistant, and xylobiose was not hydrolyzed.

\section{REFERENCES}

1) H. Yoshioka, S. Chavanich, N. Nilubol and S. Hayashida, Agric. Biol. Chem., 45, 579 (1981).

2) H. Yoshioka, N. Nagato, S. Chavanich, N. Nilubol and S. Hayashida, Agric. Biol. Chem., 45, 2425
(1981).

3) M. Matsuo, T. Yasui and T. Kobayashi, Nippon Nôgeikagaku Kaishi, 49, 263 (1975).

4) M. Matsuo, T. Yasui and T. Kobayashi, Agric. Biol. Chem., 41, 1593 (1977).

5) M. Matsuo, T. Yasui and T. Kobayashi, Agric. Biol. Chem., 41, 1601 (1977).

6) M. Matsuo and T. Yasui, Agric. Biol. Chem., 45, 1603 (1981).

7) D. J. Davis, Ann. N. Y. Acad. Sci., 121, 404 (1964).

8) I. Kusakabe, T. Yasui and T. Kobayashi, Agric. Biol. Chem., 39, 1355 (1975); I. Kusakabe, T. Yasui and T. Kobayashi, Nippon Nôgeikagaku Kaishi, 49, 383 (1975).

9) W. R. Fernell and H. K. King, Analyst, 78, 80 (1953).

10) M. Somogyi, J. Biol. Chem., 195, 19 (1952).

11) M. Somogyi, J. Biol. Chem., 161, 61 (1945).

12) J. D. Allen and J. A. Thoma, Biochemistry, 17, 2338 (1978). 